\title{
Recovery of a 10-year-old girl from methicillin- resistant Staphylococcus aureus sepsis in response to low-dose ceftaroline treatment
}

This article was published in the following Dove Press journal:

Therapeutics and Clinical Risk Management

II May 2016

Number of times this article has been viewed

Stefan Borgmann,' Beate

Rieß,' Thomas von WernitzKeibel, ${ }^{2}$ Matthias Bühler, ${ }^{3}$ Franziska Layer, ${ }^{4}$ Birgit Strommenger ${ }^{4}$

'Department of Infectious Diseases and Infection Control, ${ }^{2}$ Department of Anaesthesiology and Intensive Care Medicine, ${ }^{3}$ Department of Trauma Surgery, Klinikum Ingolstadt, Ingolstadt, ${ }^{4} \mathrm{National}$ Reference Centre for Staphylococci and Enterococci, Division Nosocomial Pathogens and Antibiotic Resistances, Department for Infectious Diseases, Robert Koch Institute, Wernigerode Branch, Wernigerode, Germany

\section{Video abstract}

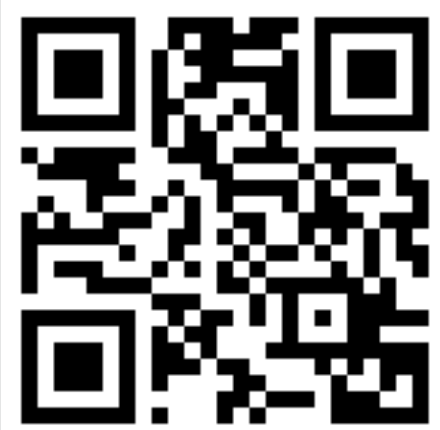

Point your SmartPhone at the code above. If you have a QR code reader the video abstract will appear. Or use: http://youtu.be/89BMo8NTGKM

Correspondence: Stefan Borgmann Department of Infectious Diseases and Infection Control, Klinikum Ingolstadt, Krumenauer Str. 25, D-85049 Ingolstadt, Germany

Tel +4984I 8802020

$\mathrm{Fax}+498418802849$

Email stefan.borgmann@klinikum-ingolstadt.de
Abstract: A 9-year-old girl was severely injured in a car accident in Afghanistan, in which both her lower legs were badly damaged. She was treated at the Hospital of Ingolstadt (Klinikum Ingolstadt) after she had undergone initial surgery at an Indian hospital. Various bacterial species were isolated from multiple wounds, and methicillin-resistant Staphylococcus aureus (MRSA) was one among them. After the amputation of her lower legs, she developed MRSA sepsis, which was successfully treated with a relatively low dosage of ceftaroline (Zinforo ${ }^{\circledR} /$ Teflaro $^{\circledR}$; $2 \times 9 \mathrm{mg} / \mathrm{kg} / \mathrm{d})$, although the bacterial isolate's minimal inhibitory concentration $(1.5-4 \mathrm{mg} / \mathrm{L})$ suggested a decreased susceptibility. In summary, ceftaroline was highly efficient and well tolerated by the patient suffering from MRSA sepsis.

Keywords: side effects, susceptibility, ceftaroline, minimal inhibitory concentration, therapy

\section{Case report}

In August 2013, a 9-year-old Afghan girl, who had been severely injured in a car accident in early 2013, was admitted to a teaching hospital in southeast Germany (Bavaria). Before her transfer to Germany, she had undergone surgery at an Indian hospital. Her left leg had been stabilized with an external fixation, which was later substituted by a femur nail.

On admission, her general condition dramatically deteriorated. She was dehydrated and undernourished (130 cm height, $25 \mathrm{~kg}$ body weight) as indicated by decreased serum concentration of total protein $(42.3 \mathrm{mg} / \mathrm{dL}$ [normal range $66.0-83.0 \mathrm{mg} / \mathrm{dL}$ ]) and creatinine $(0.3 \mathrm{mg} / \mathrm{dL}[0.6-0.9 \mathrm{mg} / \mathrm{dL}])$. She also suffered from anemia and several decubitus dorsal ulcers (stage 2 and 3). Both legs showed multiple wounds with extended areas of scab which secreted large amounts of yellow pus. Pus was also secreted from a fistula of her left hip joint.

Various bacteria species exhibiting extensive antibiotic resistances were isolated from swabs of the patients wounds: methicillin resistant Staphylococcus aureus (MRSA); carbapenem resistant Pseudomonas aeruginosa; and several Gram negative bacteria species with extended spectrum beta-lactamase activity (ESBL); Citrobacter sedlakii; Escherichia coli; Proteus mirabilis; Klebsiella pneumoniae. Furthermore, methicillin susceptible $S$. aureus, P. mirabilis (non ESBL), Enterococcus faecalis, Enterococcus hirae, Bacteroides fragilis, and peptostreptococci were identified. Bacterial identification and antibiotic susceptibility testing was performed as recently described. ${ }^{1}$

After 2 weeks of initial treatment at the intensive care unit, the patient was admitted to the pediatric surgery ward as her general condition had significantly improved. Until June 2014, she underwent 16 surgeries and approximately 60 dressing changes, each requiring 
general anesthetics. During her stay, she received the following antibiotics in dosages adapted to her body weight: cefazoline ( $1 \mathrm{~g}$ two times per day; $2 \times 1 \mathrm{~g} / \mathrm{d})$, imipenem $(4 \times 0.5 \mathrm{~g} / \mathrm{d})$, meropenem $(3 \times 400 \mathrm{mg} / \mathrm{d})$, ampicillin $(3 \times 400 \mathrm{mg} / \mathrm{d})+$ clindamycin $(3 \times 150 \mathrm{mg} / \mathrm{d})$ intravenously, amoxicillin $(3 \times 400 \mathrm{mg} / \mathrm{d})+$ clindamycin $(3 \times 150 \mathrm{mg} / \mathrm{d})$ orally, ceftazidime $(3 \times 1 \mathrm{~g} / \mathrm{d})$, ceftaroline (Zinforo ${ }^{\circledR}$ [AstraZeneca, London, UK]/Teflaro ${ }^{\circledR}$ [Allergan, Dublin, Ireland]; $2 \times 225 \mathrm{mg} / \mathrm{d}$ ), and cefuroxime $(2 \times 250 \mathrm{mg} / \mathrm{d})$ (Figure 1A).

MRSA was frequently isolated from various body sites within the first 3 weeks after admission (Figure 1B). Following two decolonization cycle, MRSA was not found in several swabs taken from the nose and throat nor isolated from the biopsy specimen taken from September 16, 2013 to March 20,2014 . There was no further proof of MRSA over this time, except for a nose swab taken on March 20, 2014, leading to decolonization measures for seven additional days.

On May 16, 2014, MRSA was found in a biopsy sample and it was also found afterwards in swabs taken from the nose and throat. On June 3, 2014, the patient underwent amputation of her lower legs (knee disarticulation) and MRSA was detected in a biopsy of the infected limb. After surgery, the patient was treated for 9 days in the intensive care unit due to a deterioration in her general condition. As shown in Figure 2, systemic inflammatory response syndrome was present, as indicated by an increased heart rate $(140 / \mathrm{bpm})$, white blood cell count $\left(>24,200 / \mathrm{mm}^{3}\right)$, and decreased blood pressure (systolic arterial pressure $80-100 \mathrm{mmHg}$ ). ${ }^{2}$ Body temperature rose to $40.3^{\circ} \mathrm{C}$ and C-reactive protein concentration increased to $265.5 \mathrm{mg} / \mathrm{L}$. MRSA was found in a blood culture, indicating septic infection.

In the following days, antibiotic treatment with ceftaroline $(2 \times 225 \mathrm{mg} / \mathrm{d})$ led to a continuous improvement of her general condition. On June 18, 2014, she underwent a final revision surgery of her right thigh wound, including removal of the condylar cartilage and debridement of necrotic tissue. Although MRSA was detected in a biopsy specimen removed during this surgery, there was no increase of inflammation parameters nor was the circulation impaired. Ceftaroline application was

A

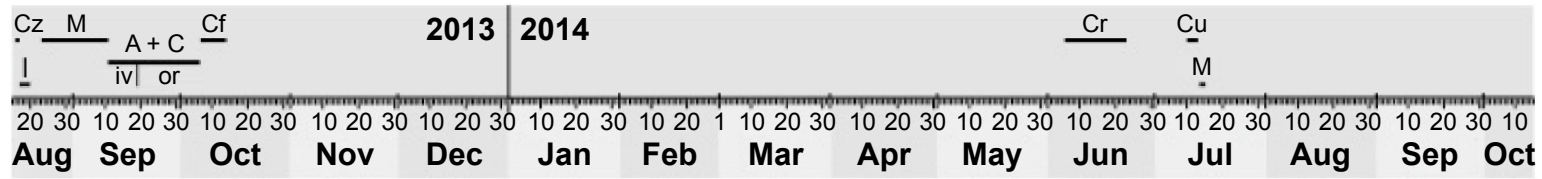

B

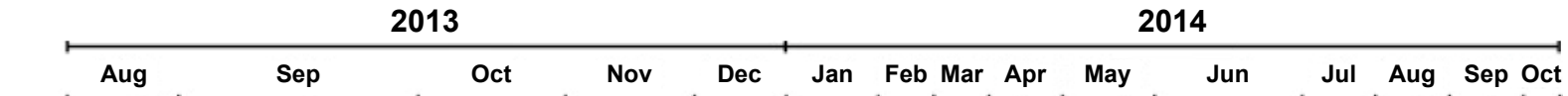

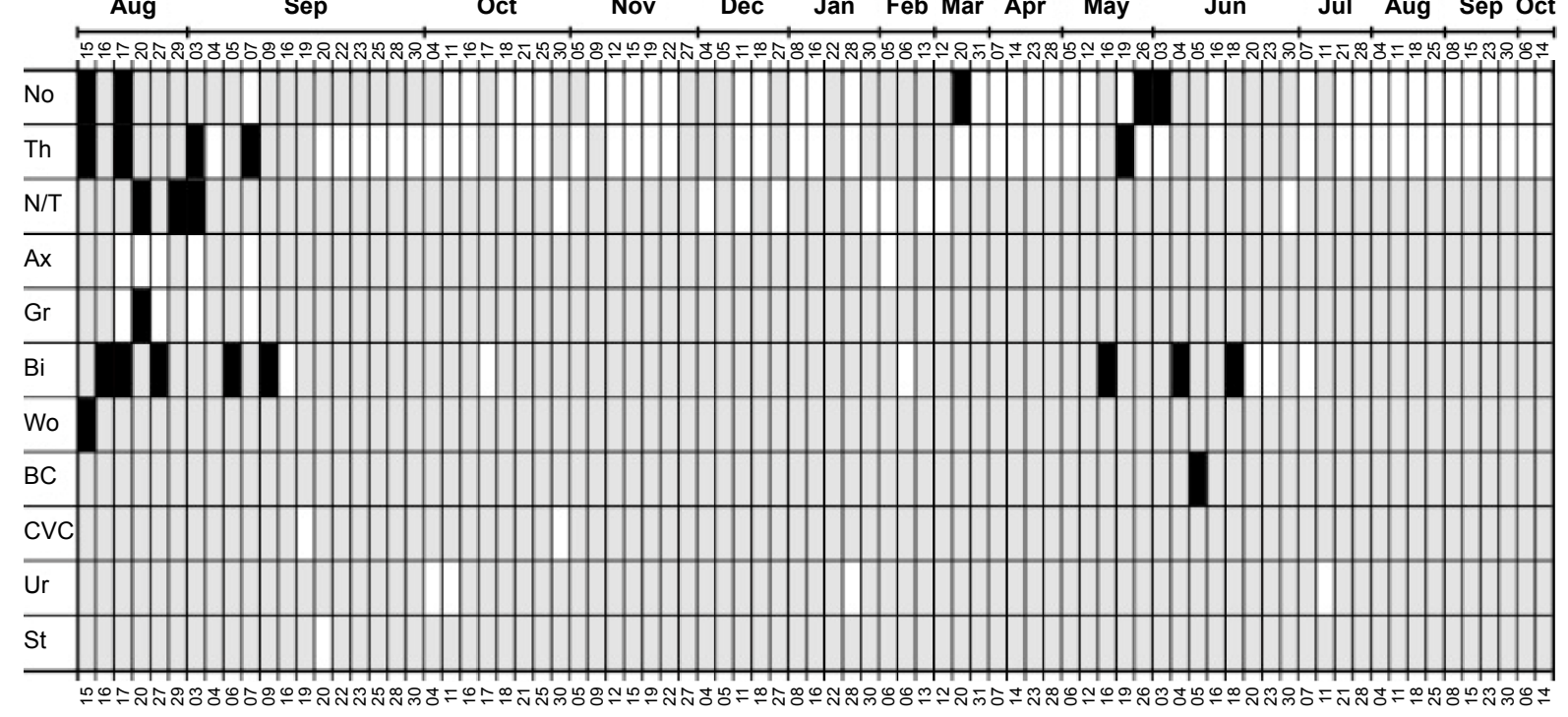

MRSA present MRSA not present MRSA analysis not performed

Figure I Microbiological results and antibiotic treatment.

Notes: (A) Antibiotics applied during hospital stay. (B) Results of microbiological analyses performed during hospital stay with regard to MRSA. Swabs were taken from nose, throat, nose and throat, axilla, groin, biopsy, wound, blood culture, central vein catheter, urine, and stool. For N/T analysis, two swabs were taken, but the result did not discriminate between both swabs.

Abbreviations: A + C, ampicillin/amoxicillin and clindamycin; Ax, axilla; BC, blood culture; $\mathrm{Bi}$, biopsy; Cf, ceftazidime; $\mathrm{Cr}$, ceftaroline; Cu, cefuroxime; CVC, central vein catheter; Cz, cefazoline; Gr, groin; I, imipenem; iv, intravenous application; M, meropenem; MRSA, methicillin-resistant Staphylococcus aureus; No, nose; N/T, nose and throat; or, oral application; St, stool; Th, throat; Ur, urine; Wo, wound. 


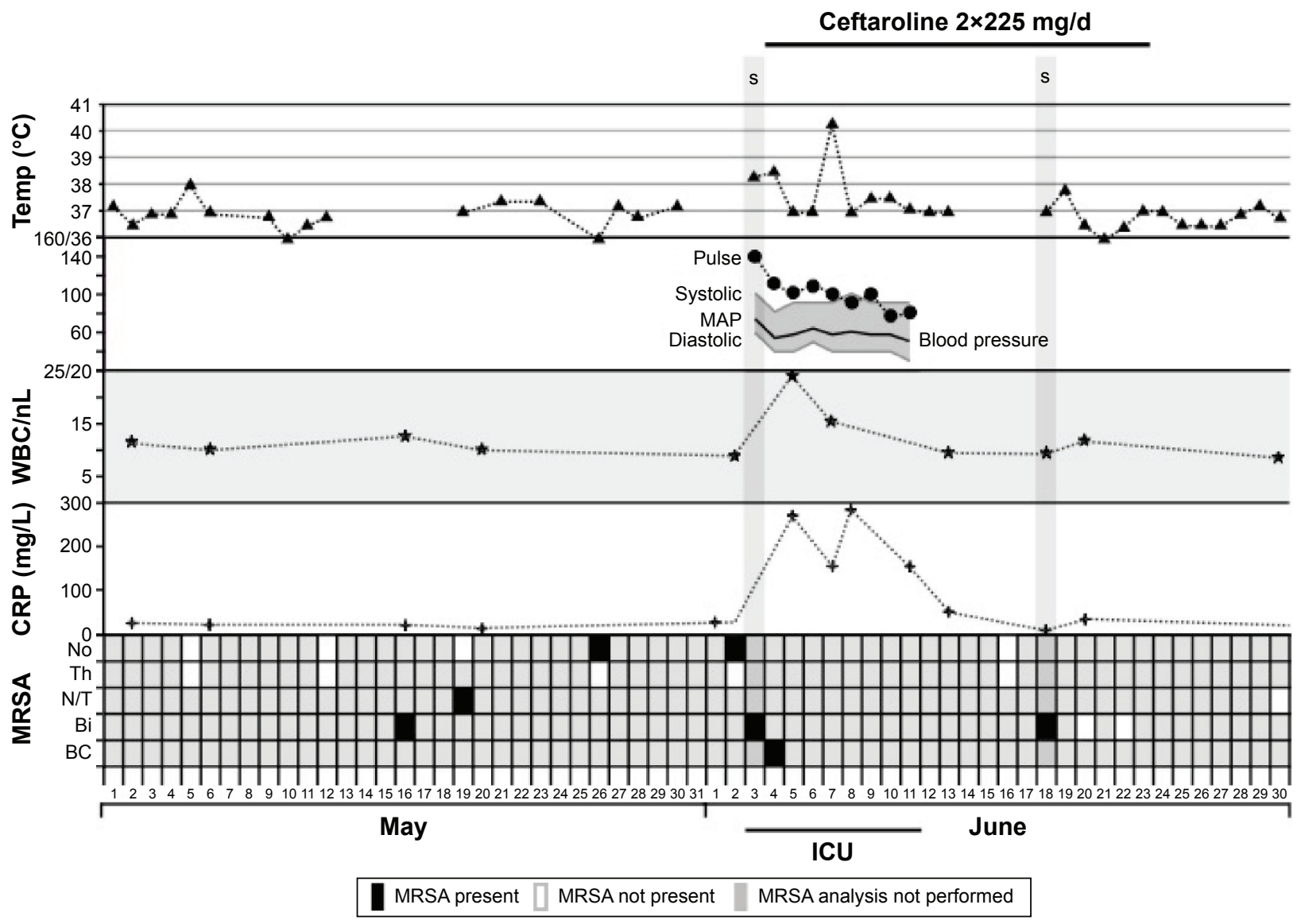

Figure 2 Vital signs of the presented patient between May and June 2014.

Notes: Similar to Figure I, the lowest line shows microbiological results in regard to MRSA finding. MAP was calculated by using the formula: MAP = diastolic blood pressure $+\mathrm{I} / 3$ (systolic - diastolic blood pressure).

Abbreviations: BC, blood culture; $\mathrm{Bi}$, biopsy; CRP, C-reactive protein; ICU, intensive care unit; MAP, mean arterial pressure (mmHg); MRSA, methicillin-resistant Staphylococcus aureus; No, nose; N/T, nose and throat; S, surgery; temp, temperature $\left({ }^{\circ} \mathrm{C}\right)$; Th, throat; WBC, white blood cell count.

stopped after a treatment period of 19 days. No further MRSA was found in any of the swabs taken from the nose and throat and she was discharged from the hospital in October 2014.

Typing of two MRSA isolates was performed by the National Reference Centre for Staphylococci and Enterococci at the Robert Koch Institute, Wernigerode, Germany and the results are summarized in Table 1. Informed consent was given by the patients legal representative. Ethics approval was not deemed necessary by the Institutional Review Board of Klinikum Ingolstadt as only standard treatment procedures were carried out and no additional samples were taken for scientific purposes.

\section{Discussion}

In this report, we present a young patient with severe infection of both legs, caused by a multitude of (multiresistant) bacteria. Bacteriologic analyses intermittently revealed the presence of MRSA, and after amputation surgery, the patient

Table I Characteristics of MRSA isolates

\begin{tabular}{|c|c|c|c|c|c|c|c|c|c|}
\hline \multirow[t]{2}{*}{ No } & \multirow[t]{2}{*}{ Date of isolation } & \multirow[t]{2}{*}{ Body site } & \multirow[t]{2}{*}{ spa type ${ }^{a}$} & \multirow[t]{2}{*}{$\mathrm{CC}^{\mathrm{b}}$} & \multirow[t]{2}{*}{$\mathrm{SCCmec}^{\mathrm{c}}$} & \multirow[t]{2}{*}{$\begin{array}{l}\text { PVLd }^{d} \\
\operatorname{arcA}^{d}\end{array}$} & \multirow[t]{2}{*}{$\begin{array}{l}\text { Phenotypic } \\
\text { resistance pattern }\end{array}$} & \multicolumn{2}{|c|}{$\begin{array}{l}\text { MIC ceftaroline } \\
\text { (mg/L) }\end{array}$} \\
\hline & & & & & & & & BMD $^{e, f}$ & Etest $^{\mathrm{f}, \mathrm{g}}$ \\
\hline I & August 15,2013 & Nose & t064 & $\mathrm{CC} 8$ & IV- & - & PEN, OXA, GEN, CIP, SXT, MFL & $2(\mathrm{~ns})$ & $\mathrm{I} .5$ (ns) \\
\hline 2 & June 3,2014 & Blood culture & t064 & $\mathrm{CC} 8$ & IV- & - & PEN, OXA, GEN, CIP, SXT, MFL & 4 (ns) & $2(n s)$ \\
\hline
\end{tabular}

Notes: ${ }^{\text {AAll }}$ Staphylococcus aureus strains isolated were typed by analyzing the repetitive X-region of the protein A gene (spa) as described previously. ${ }^{13}$ bBased on spa-typing results, isolates were assigned to clonal complexes reflecting their genetic relatedness among the $S$. aureus population. ${ }^{13} \mathrm{SCC}$ ( $\mathrm{Cec}$ type was investigated as described previously..$^{13}$ ${ }^{-}$The presence of PVL-encoding lukF-lukS-PV and arcA was analyzed by PCR according to Strommenger et al. ${ }^{14}$ eBMD was performed and evaluated according to EUCAST guidelines. ${ }^{10,15}{ }^{5}$ Etest (Biomerieux, Nürtingen, Germany) was performed according to the manufacturer's instructions. 8 Interpretation of MICs according to EUCAST guidelines. ${ }^{15}$ Abbreviations: BMD, broth microdilution; CC, clonal complex; CIP, ciprofloxacin; GEN, gentamicin; MFL, moxifloxacin; MIC, minimal inhibitory concentration; MRSA, methicillin-resistant Staphylococcus aureus; ns, nonsusceptible; OXA, oxacillin; PCR, polymerase chain reaction; PEN, penicillin; PVL, Panton-Valentine leukocidin; SCC, staphylococcal chromosome cassette; SXT, trimethoprim/sulfamethoxazole. 
developed sepsis caused by this particular bacterial species. Typing results indicated an endogenous MRSA infection, although screening results had suggested successful prior MRSA decolonization. Screening and decolonization of $S$. aureus in orthopedic patients is an effective measure to prevent endogenous infection and subsequent bacteremia. ${ }^{3}$ However, in this case, it is questionable whether decolonization measures proved efficient, due to the underlying conditions of the patient. Moreover, the screening results presented demonstrate the risk of MRSA recolonization in high-risk patients, which underlines the importance of continuous MRSA monitoring.

The infection was successfully treated with ceftaroline. This antibiotic was chosen because a greater efficiency in comparison to vancomycin and linezolid was anticipated. Despite the promising reports on the use of daptomycin in pediatric patients, we forewent usage of this drug due to limited treatment experiences in children at our hospital. ${ }^{4}$

Since ceftaroline is not approved for use in children, information about appropriate ceftaroline dosage, safety, and efficacy in children is scarce. ${ }^{5,6}$ A study examining the safety of $3 \times 12 \mathrm{mg} / \mathrm{kg} / \mathrm{d}$ ceftaroline for pediatric patients of $<33 \mathrm{~kg}$ body weight has recently been completed, but its results have not been published yet. ${ }^{7}$ In a recent case report on ceftaroline treatment of MRSA pneumonia in a 6-year-old boy, a comparable initial dose of $2 \times 9.7 \mathrm{mg} / \mathrm{kg} / \mathrm{d}$ had been applied. During the course of treatment, the dosage was increased to $3 \times 10.8 \mathrm{mg} / \mathrm{kg} / \mathrm{d}$ and it did not produce any side effects. ${ }^{8}$

With respect to body weight and the general condition of the patient described herein, initial therapy was started with a relatively low dosage $(2 \times 9 \mathrm{mg} / \mathrm{kg} / \mathrm{d}) .{ }^{9}$ As the postoperative course was satisfactory, the low-dose treatment was continued.

Within 4 days of treatment, the patient's circulation stabilized and body temperature decreased, while C-reactive protein concentration and white blood cell count remained increased for another week, which was probably due to the extended wounds on her thighs. The patient's temperature rose once again to $40.3^{\circ} \mathrm{C}$, probably caused by dissemination of bacteria from the remaining infected tissue into circulation. After a final revision surgery, inflammation parameters remained low.

In vitro analysis displayed an increased minimal inhibitory concentration (MIC) of $1.5-4 \mathrm{mg} / \mathrm{L}$ for MRSA from blood culture, suggesting reduced antibiotic susceptibility to ceftaroline. Reduced preuse susceptibility to ceftaroline has been reported worldwide, predominantly in MRSA belonging to certain clonal lineages (ST228 and ST239). ${ }^{10}$ The strains isolated in this case belong to a different clonal lineage (CC8); however, their isolation demonstrates that ceftaroline resistance might occur in MRSA in general.

Increased ceftaroline MICs reported in literature remain relatively low $(1.5-4 \mathrm{mg} / \mathrm{L})$ and it is not yet clear whether these MICs influence treatment efficiency. Therefore, changing the susceptibility interpretive criteria to an MIC of $\leq 2.0 \mathrm{mg} / \mathrm{L}$ was suggested recently based on pharmacokinetic and pharmacodynamic in vitro analyses. ${ }^{11}$ However, due to diagnostic challenges in susceptibility testing, ceftaroline MIC of $1.0 \mathrm{mg} / \mathrm{L}$ remains an important and conservative breakpoint to sensitize clinicians for putative treatment failure and to preserve ceftaroline as a potent antibiotic for serious infections caused by broadly resistant MRSA. ${ }^{10,12}$

\section{Disclosure}

SB received speaker's honorarium from AstraZeneca. The authors report no other conflicts of interest in this work.

\section{References}

1. Steger S, Demetz F, Schmidt C, Borgmann S. Low percentage of asylum seekers colonized with multi-resistant bacteria treated at a German hospital. J J Epidemiol Prevent. 2016;1(2):21.

2. Goldstein B, Giroir B, Randolph A; International Consensus Conference on Pediatric Sepsis. International pediatric sepsis consensus conference: definitions for sepsis and organ dysfunction in pediatrics. Pediatr Crit Care Med. 2005;6(1):2-8.

3. Chen AF, Wessel CB, Rao N. Staphylococcus aureus screening and decolonization in orthopaedic surgery and reduction of surgical site infections. Clin Orthop Relat Res. 2013;471(7):2383-2399.

4. Principi N, Caironi M, Venturini F, Pani L, Esposito S. Daptomycin in paediatrics: current knowledge and the need for future research. J Antimicrob Chemother. 2015;70(3):643-648.

5. Gostelow M, Gonzalez D, Smith PB, Cohen-Wolkowiez M. Pharmacokinetics and safety of recently approved drugs used to treat methicillin-resistant Staphylococcus aureus infections in infants, children and adults. Expert Rev Clin Pharmacol. 2014;7(3):327-340.

6. Mpenge MA, MacGowan AP. Ceftaroline in the management of complicated skin and soft tissue infections and community acquired pneumonia. Ther Clin Risk Manag. 2015;11:565-579.

7. Forest Laboratories. Safety and efficacy study of ceftaroline versus a comparator in pediatric subjects with community acquired bacterial pneumonia (CABP) [updated January 12, 2015]. Available from: https:/clinicaltrials.gov/ct2/show/NCT01530763/. ClinicalTrials.gov Identifier: NCT01530763. Accessed August 11, 2015.

8. Molloy L, Snyder AH, Srivastava R, Rybak MJ, McGrath E. Ceftaroline fosamil for methicillin-resistant Staphylococcus aureus pulmonary exacerbation in a pediatric cystic fibrosis patient. J Pediatr Pharmacol Ther. 2014;19(2):135-140.

9. Jain R, Chan JD, Rogers L, Dellit TH, Lynch JB, Pottinger PS. High incidence of discontinuations due to adverse events in patients treated with ceftaroline. Pharmacotherapy. 2014;34(7):758-763.

10. Strommenger B, Layer F, Klare I, Werner G. Pre-use susceptibility to ceftaroline in clinical Staphylococcus aureus isolates from Germany: Is there a non-susceptible pool to be selected? PLoS One. 2015;10(5): e0125864.

11. Van Wart SA, Ambrose PG, Rubino CM, et al. Pharmacokineticpharmacodynamic target attainment analyses to evaluate in vitro susceptibility test interpretive criteria for ceftaroline against Staphylococcus aureus and Streptococcus pneumoniae. Antimicrob Agents Chemother. 2014;58(2):885-891. 
12. Livermore DM, Mushtaq S, Warner M, James D, Woodford N. Susceptibility testing challenges with ceftaroline, MRSA and a $1 \mathrm{mg} / \mathrm{L}$ breakpoint. J Antimicrob Chemother. 2015;70(12):3259-3266.

13. Strommenger B, Braulke C, Heuck D, et al. spa Typing of Staphylococcus aureus as a frontline tool in epidemiological typing. J Clin Microbiol. 2008;46(2):574-581.

14. Strommenger B, Braulke C, Pasemann B, Schmidt C, Witte W. Multiplex PCR for rapid detection of Staphylococcus aureus isolates suspected to represent community-acquired strains. J Clin Microbiol. 2008;46(2):582-587.
15. EUCAST: The European Committee on Antimicrobial Susceptibility Testing. Breakpoint tables for interpretation of MICs and zone diameters. Version 5.0; 2015 [updated January 26, 2015]. Available from: http://www.eucast.org/fileadmin/src/media/PDFs/EUCAST_files/ Breakpoint_tables/v_5.0_Breakpoint_Table_01.pdf. Accessed August 11, 2015.

\section{Publish your work in this journal}

Therapeutics and Clinical Risk Management is an international, peerreviewed journal of clinical therapeutics and risk management, focusing on concise rapid reporting of clinical studies in all therapeutic areas, outcomes, safety, and programs for the effective, safe, and sustained use of medicines. This journal is indexed on PubMed Central, CAS,
EMBase, Scopus and the Elsevier Bibliographic databases. The manuscript management system is completely online and includes a very quick and fair peer-review system, which is all easy to use. Visit http://www.dovepress.com/testimonials.php to read real quotes from published authors.

Submit your manuscript here: http://www.dovepress.com/therapeutics-and-clinical-risk-management-journal 